\title{
Durability of Wearable Antennas Based on Nonwoven Conductive Fabrics: Experimental Study on Resistance to Washing and Ironing
}

\author{
Laura Corchia $\mathbb{D}^{D}$, Giuseppina Monti $\mathbb{D}^{D}$, and Luciano Tarricone \\ Department of Innovation for Engineering, University of Salento, Lecce 73014, Italy \\ Correspondence should be addressed to Giuseppina Monti; giuseppina.monti@unisalento.it
}

Received 19 July 2018; Accepted 2 September 2018; Published 14 October 2018

Guest Editor: Haider Raad

Copyright (C) 2018 Laura Corchia et al. This is an open access article distributed under the Creative Commons Attribution License, which permits unrestricted use, distribution, and reproduction in any medium, provided the original work is properly cited.

\begin{abstract}
Adhesive nonwoven conductive fabrics are appealing materials for fabricating fully textile antennas for wearable wireless systems. Wearable antennas should be flexible, lightweight, and mechanically resistant. Additionally, the antenna performance should be robust to activities related to daily use of garments, such as washing and ironing. Accordingly, in this work, the results of several washing tests performed on fully textile antennas fabricated by exploiting three different adhesive nonwoven conductive fabrics are reported.
\end{abstract}

\section{Introduction}

Antennas play a key role in wearable wireless monitoring systems. These devices must be conformal, lightweight, flexible, and nonintrusive for the users. This last requirement is mandatory for applications requiring highly embeddable systems, such as those intended for noncooperative users, e.g., health-care monitoring of elderly people [1-6] or newborns [7, 8], localization of people with Alzheimer [9], and athlete performance monitoring $[10,11]$.

To satisfy all the aforementioned requirements and to make the integration in the garments easier, it is crucial to select the most suitable fabrication technique and the related materials. In particular, to obtain a seamless integration of the antenna into garments, the best choice consists in using textile materials for both the substrate and the conductive parts. As per the substrate, it is possible to employ materials that are typically used in the clothing industry, such as cotton, jeans, and pile, while, for implementing the conductive parts of the antenna, the use of different materials has been proposed and tested in the literature [12-33]. Among these, particularly attractive are (i) nonwoven conductive fabrics (NWCFs) [12-18], (ii) conductive threads [19-27], and (iii) electrotextiles [28-33].
In particular, in the last years, great attention has been paid to the use of NWCFs which guarantee the optimal trade-off between achievable performance and efforts associated with the design and the manufacturing process. In fact, with respect to electrotextiles, NWCFs present the advantage of having properties similar to those of woven fabrics (flexibility, mechanical resistance, washability, conductivity, etc.) associated with no fraying problems. Additionally, in electromagnetic simulation tools, NWCFs can be modelled as a homogeneous layer, and this represents a considerable benefit with respect to conductive threads which require an accurate numerical model of the embroidered pattern [20-22, 34, 35].

Another key aspect of wearable antennas is their durability in terms of robustness of the performance to operations to which garments are commonly subjected. In particular, it is crucial that wearable devices and antennas should not be affected by washing, drying, ironing, etc. Furthermore, their "service-life" should be equal to that of the clothes in which they are integrated $[36,37]$.

In the literature, several works have focused on the durability analysis of wearable antennas fabricated exploiting different conductive materials, such as electrotextiles [36], conductive threads [37], and conductive inks [38]. Nevertheless, so far, no work has addressed systematically the 


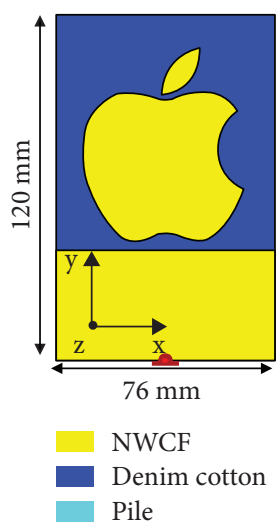

(a)
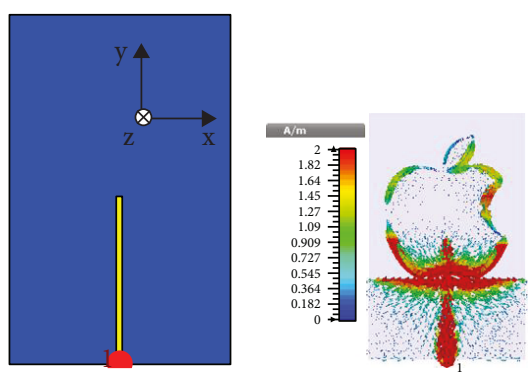

(b) (c)

Figure 1: Original design: (a) front view; (b) back view; (c) surface current distribution at $2.5 \mathrm{GHz}$.

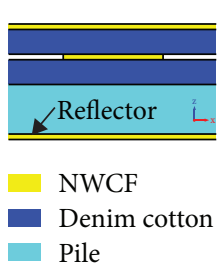

(a)

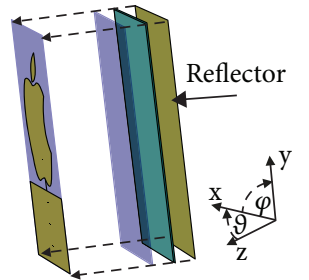

(b)

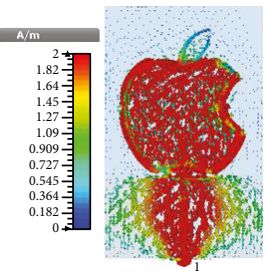

(c)

FIgURE 2: Modified design: (a) side view; (b) prospective view; (c) surface current distribution at $2.5 \mathrm{GHz}$.

durability of NWCF-based wearable antennas. On such bases, in this paper, the durability of wearable antennas based on the use of adhesive NWCFs is investigated. Three different conductive materials were used for fabricating three prototypes having the same geometry.

The paper is structured as follows. In Section II, the geometry of the analyzed antennas is presented and some details on the design process, the materials, and the manufacturing techniques are given. In the same section, the results of the measurements performed on the prototypes before durability tests are also reported. In Section III, the results of the repeated washing cycles are reported and discussed. Finally, in Section IV, conclusions are drawn.

\section{NWCF-Based Wearable Antennas}

2.1. Antenna Geometry and Numerical Performance. The geometry of the antenna exploited for performing the durability tests is a modified version of the antenna presented in [17]. The original design consists of a proximity-fed monopole on a ground plane (see Figure 1). The radiating element mimics the logo of the multinational corporation Apple Inc. More in detail, the monopole is indirectly fed by a capacitive coupling with a $50 \Omega$ microstrip line with which shares the same ground plane; the coupling mechanism induces a surface current on the radiating element as shown in Figure 1(c). This geometry presents a dipole-like radiation pattern, i.e., an omnidirectional radiation in the plane perpendicular to the one of the antenna (referring to Figure 1(a), a radiation pattern omnidirectional in the xzplane). This feature makes the original design suitable for applications such as anticounterfeiting or item tracking and localization during logistic management and retail. In fact, for these applications, the antenna is exploited when the garments are not worn and an omnidirectional radiation pattern is preferred to facilitate the reading of the data of interest.

Vice versa, when the antenna operates in the proximity of the human body, hence when it is worn (for instance, consider the case of smart clothes for ubiquitous health and activity monitoring), a patch-like radiation pattern is preferable. In fact, this configuration exhibits a high front-to-back ratio, thus leading to a performance robust with respect to the surface of application which is a required feature for antennas operating in close proximity to the human body.

Accordingly, to make the antenna proposed in [17] suitable to be also used for on-body wearable applications, the authors have investigated the possibility of using a reflector plane in order to achieve a patch-like radiation pattern.

The basic idea is to use the antenna with or without reflector depending on the specific application of interest; in other words, the reflector plays the role of an adapter that matches the antenna to the use in proximity of the human body.

Hence, the performance of the proposed antenna was investigated in the presence of a reflector placed as shown in Figures 2(a) and 2(b). As it can be seen, a multilayer structure having a total thickness of $1.61 \mathrm{~mm}$ was overlapped to the feed-line. The multilayer consists of a layer of denim cotton, a layer of pile, and finally a layer of NWCF.

The dimensions of the feed-line were optimized (width equal to $2 \mathrm{~mm}$ and length equal to $57.5 \mathrm{~mm}$ ) through fullwave simulations performed with CST Microwave Studio to match the antenna impedance to $50 \Omega$ at $2.5 \mathrm{GHz}$, both 


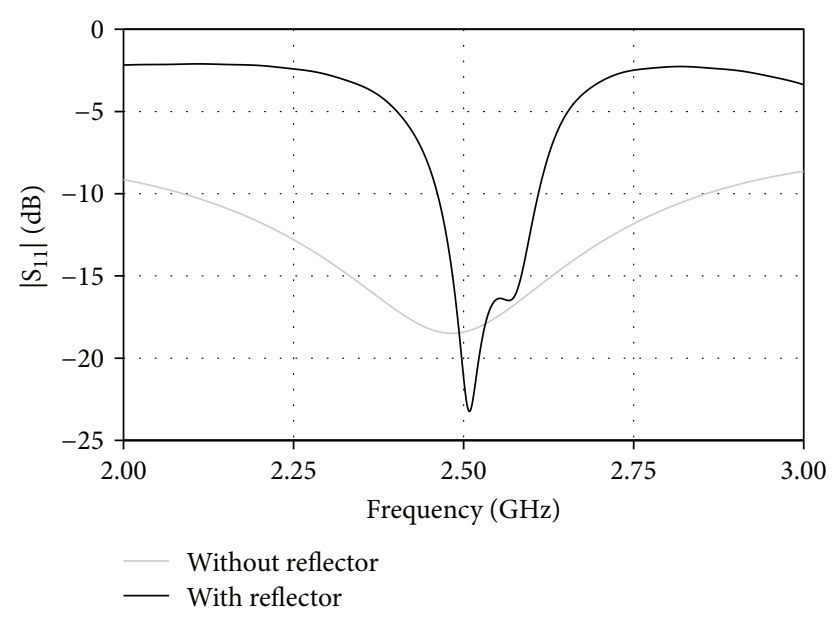

Figure 3: Simulated results achieved for the $\left|S_{11}\right|$ : the black curve corresponds to the simulation performed with reflector, while the grey curve is the result of the simulation performed without reflector.

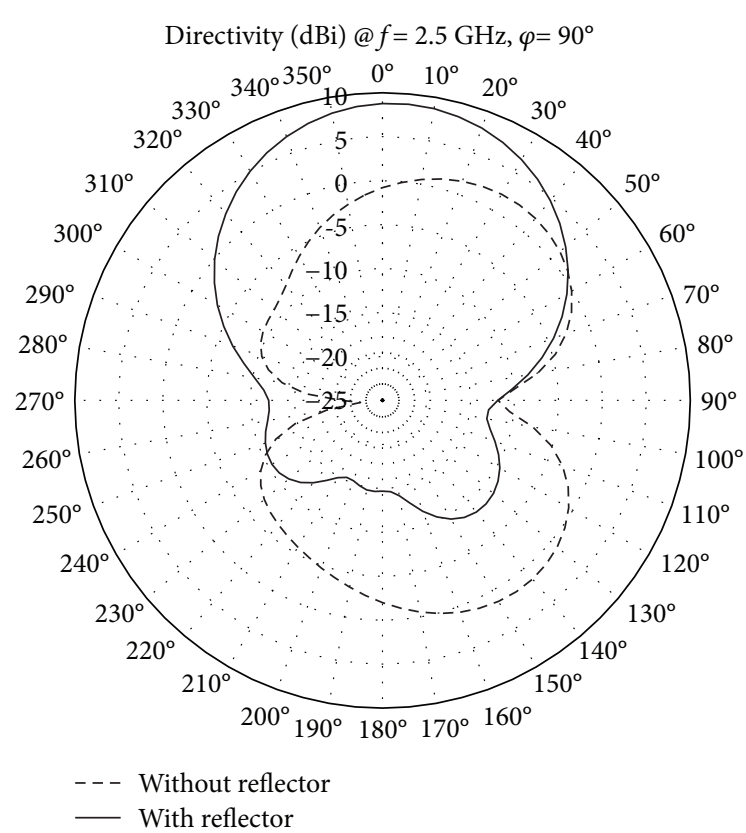

Figure 4: Numerical result comparison between directivity achieved for the antenna without (black dashed line) and with the reflector (black line).

with and without the reflector. The simulation results for the $\left|S_{11}\right|$, calculated with and without reflector, are reported in Figure 3. At $2.5 \mathrm{GHz}$, a value lower than $-15 \mathrm{~dB}$ was achieved for both configurations.

As per the radiation properties, the comparison between numerical results (obtained with and without reflector) are reported in Figure 4. As it can be seen, the presence of the conductive layer allows to achieve a patch-like radiation pattern, and it also increases the gain of the antenna in the forward direction. In particular, at $2.5 \mathrm{GHz}$ in the direction of maximum radiation $\left(\varphi=90^{\circ}, \vartheta=4^{\circ}\right)$, the antenna with reflector has a directivity of approximately $8.82 \mathrm{dBi}$. With

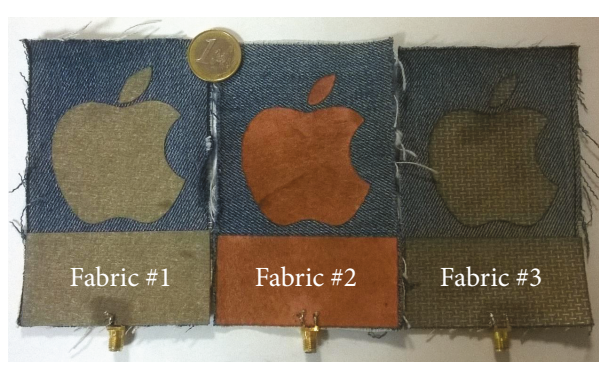

Figure 5: Picture of the fabricated prototypes.

regard to the front-to-back ratio, a value of about $23.4 \mathrm{~dB}$ was achieved.

2.2. Manufacturing Techniques and Materials. Durability tests have been performed on three different NWCFs. In particular, for the realization of the conductive parts of the three prototypes, the following fabrics were exploited:

(1) an adhesive nonwoven produced by ADFORS Saint-Gobain [39] (Fabric \#1) with thickness (th) and surface resistivity $(\rho)$ equal to $0.11 \mathrm{~mm}$ and to $0.04 \Omega /$ sq, respectively

(2) adhesive nonwoven RS-Cu-C4 (Fabric \#2) produced by Soliani EMC [40] with th $=0.15 \mathrm{~mm}$ and $\rho=0.03 \Omega / \mathrm{sq}$

(3) adhesive nonwoven PBN II 1.3 (Fabric \#3) produced by Soliani EMC [40] with th $=0.15 \mathrm{~mm}$ and $\rho=0.02 \Omega / \mathrm{sq}$

As a substrate, a layer of denim cotton with a thickness of about $0.5 \mathrm{~mm}$ was exploited.

Two different manufacturing techniques were adopted for shaping the conductive nonwoven. In particular, the Fabric \#1 was shaped by means of a cutting plotter, whereas a laser cutting machine was used for shaping the Fabric \#2 and the Fabric \#3. The cutting plotter parameters were appropriately set in order to maximize the accuracy of the fabrication process. On the other hand, the parameters of the laser machine could not be optimized since the cutting was kindly carried out by the manufacturer of the conductive materials in their own facilities. In this regard, it is worth mentioning that an excessively high laser power could damage the fabrics, thus resulting in ragged or burned edge; therefore, to avoid these manufacturing issues, a proper optimization of the laser parameters should be performed [41]. Additionally, as proposed in [41], in order to facilitate the fabrication process and to achieve a higher accuracy, the desired pattern could be directly cut on the textile substrate. The photographs of the realized prototypes are shown in Figure 5.

2.3. Experimental Results. The frequency behavior of the fabricated prototypes was measured before performing the durability tests. A vector network analyzer (VNA) ZVA50 by Rohde \& Schwarz was exploited for the measurements, 


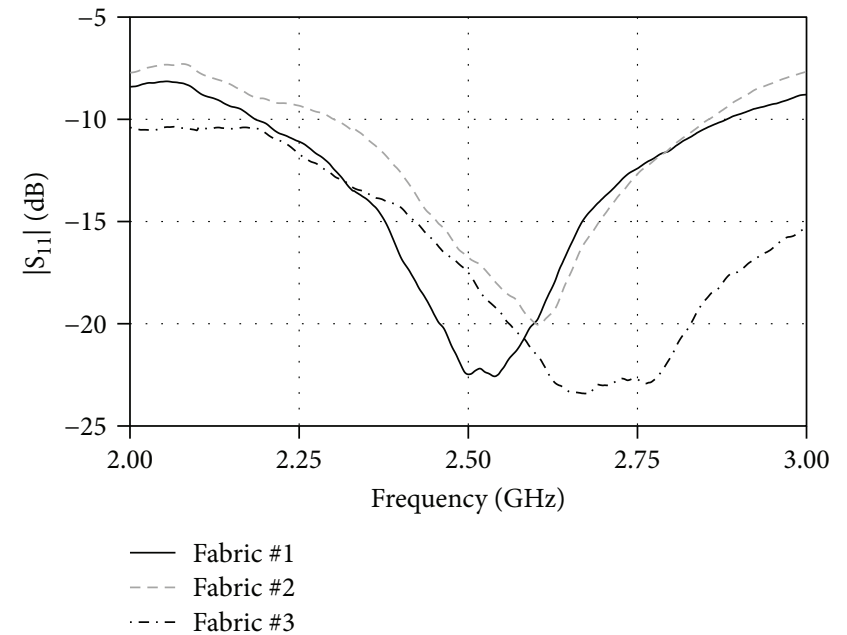

(a)

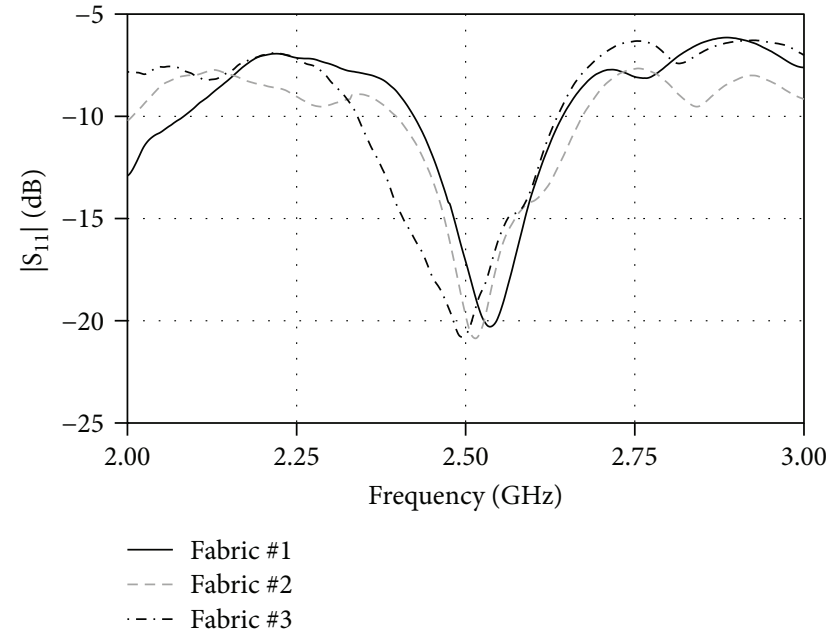

(b)

FIGURE 6: Experimental results for the $\left|S_{11}\right|$ parameter of the prototypes showed in Figure 5: (a) without reflector; (b) with reflector.

and a short-open-load (SOL) calibration was carried out at the antenna port.

Figure 6(a) shows the measured $\left|S_{11}\right|$ for the three prototypes without reflector, while the experimental results obtained in presence of the reflector are reported in Figure 6(b). Comparing Figures 3 and 6, a quite good agreement between experimental results and numerical data can be observed.

As for the radiation properties, measured data are reported in Figure 7. For each prototype, the results achieved for the antenna with and without the reflector are reported. Experimental tests were performed by using a Vector Signal Generator R\&S SMBV100A as source. The distance between the transmitting antenna (a rubber ducky antenna) and the antenna under test (AUT) was set in order to satisfy the far field region condition. In particular, considering that the most stringent condition between $d \geq 2 D^{2} / \lambda(=24 \mathrm{~cm} @$ $2.5 \mathrm{GHz})$ and $d \geq 3 \lambda(=36 \mathrm{~cm} @ 2.5 \mathrm{GHz})$ can be used, the AUT was placed $1.2 \mathrm{~m}$ far from the transmitting antenna. Both the source and the AUT were placed at $1.5 \mathrm{~m}$ from the floor. Finally, the AUT was fixed to a turntable and manually rotated. Experimental tests confirm that the presence of the reflector allows obtaining a patch-like radiation pattern and a high front-to-back ratio $(F / B)$.

Experimental results achieved for each prototype with the reflector are summarized in Table 1. The results reported in Table 1 for the antenna gain correspond to the maximum gain measured in the $\varphi=90^{\circ}$ plane. As for the $F / B$, it has been calculated as the ratio between the maximum gain measured in the $\varphi=90^{\circ}$ plane and the one measured in the opposite direction in the same plane.

\section{Results of the Durability Tests and Discussion}

To evaluate the durability of the adhesive NWCFs, the prototypes shown in Figure 5 were hand-washed repeatedly in cold water (room temperature about $28.8^{\circ} \mathrm{C}$, relative humidity of approximately $49 \%$ ). In particular, each prototype was subjected to several stress cycles, each one consisting of a washing cycle lasting 10 minutes, one of natural drying lasting 45 minutes (environmental temperature about $31.5^{\circ} \mathrm{C}$, relative humidity of approximately $47 \%$ ), and finally one of ironing. After each stress cycle, the prototypes were characterized through the VNA in order to evaluate the performance degradation in terms of frequency behavior. The results of this experimental study are summarized in Figure 8.

As for the Fabric \#1, from Figure 8(a), it is evident that the major effects of the repeated washing are an increase of the $\left|S_{11}\right|$ and a shift of the resonance towards lower frequencies. However, it can be noticed that the performance remains almost constant after the first washing cycles.

Among the three considered conductive materials, the Fabric \#2 showed the most robust performance. After eight stress cycles (see Figure 8(b)), only a slight shift of the resonance frequency was observed. This modification of the frequency behavior is likely due to the partial ungluing of the feed-line.

As for the Fabric \#3, the results of the durability test performed on the corresponding prototype are shown in Figure 8(c). Compared to Fabric \#1 and \#2, Fabric \#3 showed more degraded performance, this is likely due to issues encountered with the feed-line during manufacturing process and characterization. In particular, the dimensions of the feed-line proved to be critical; it was necessary to handle the prototypes with great care to prevent the feed-line from breaking near the welding point with the SMA connector.

In the durability test, and in particular after four washing cycles, the unsticking of the feed-line was observed for each of the three prototypes. However, during the ironing, the increase of the temperature allowed the sticking of the residual adhesive to the textile substrate; hence, the performance of the prototypes was only slightly influenced. In order to evaluate the effects of the feed-line unsticking on the antenna frequency behavior, after the fourth washing cycle, the prototypes were characterized before and after the ironing. The results are reported in Figure $8(d)$. It can be seen that the 


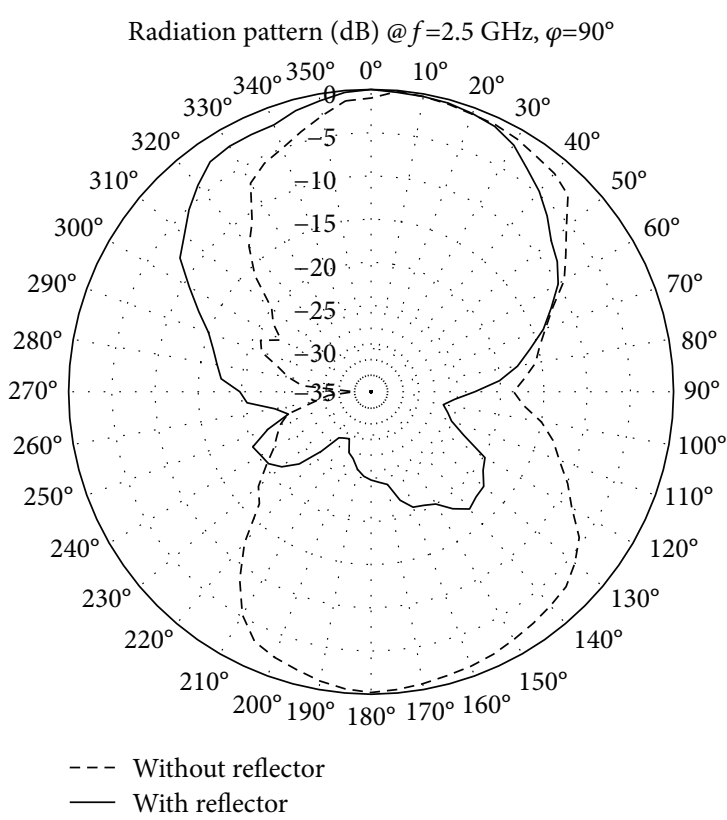

(a)

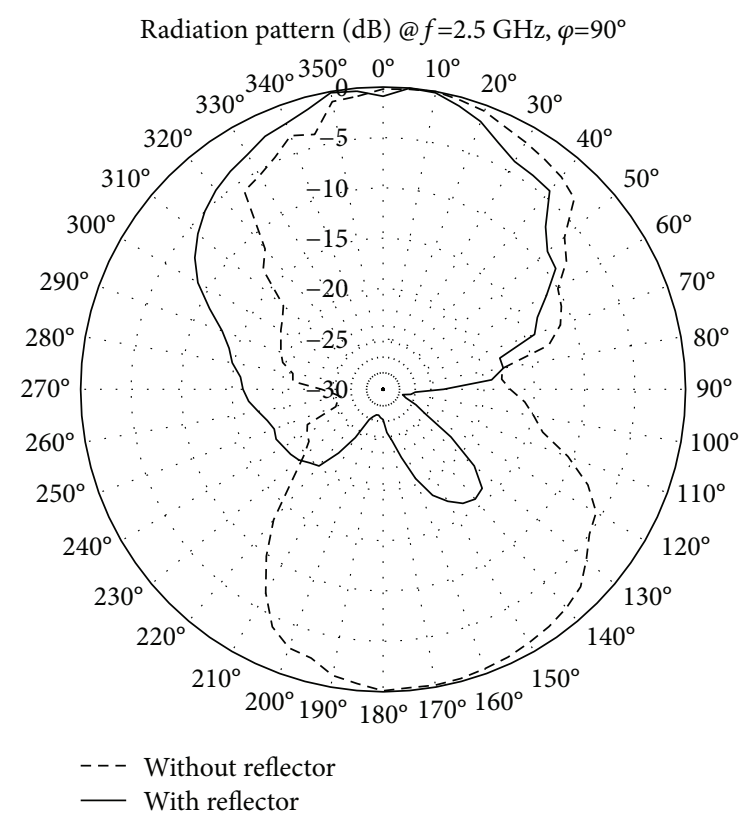

(b)

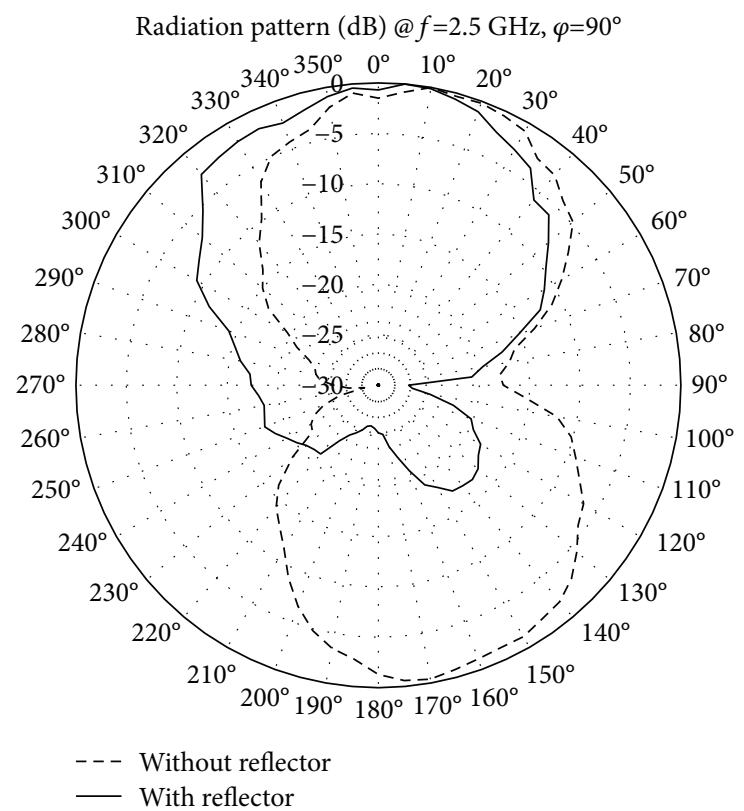

(c)

FIGURE 7: Experimental results achieved for the radiation patterns: (a) prototype fabricated exploiting Fabric \#1; (b) prototype fabricated exploiting Fabric \#2; (c) prototype fabricated exploiting Fabric \#3.

TABLE 1: Experimental data achieved for the three prototypes with the reflector.

\begin{tabular}{lcccc}
\hline $\begin{array}{l}\text { Prototype } \\
\text { (with the reflector) }\end{array}$ & $f_{0}(\mathrm{GHz})$ & $\begin{array}{c}\left|S_{11}\right|(\mathrm{dB}) \\
@ 2.5 \mathrm{GHz}\end{array}$ & $\begin{array}{c}\text { Max. gain }(\mathrm{dB}) \\
\text { @ 2.5 GHz, } \varphi=90^{\circ}\end{array}$ & $\begin{array}{c}F / B(\mathrm{~dB}) \\
\text { @ } 2.5 \mathrm{GHz}, \varphi=90^{\circ}\end{array}$ \\
\hline Fabric \#1 & 2.54 & -20.29 & 5.23 & 24.8 \\
Fabric \#2 & 2.51 & -20.86 & 5.54 & 27.2 \\
Fabric \#3 & 2.49 & -20.79 & 5.70 & 21.7 \\
\hline
\end{tabular}

resonance shifts towards higher frequencies. The worst result was achieved for the Fabric \#3, which demonstrated a $\left|S_{11}\right|$ lower than $-10 \mathrm{~dB}$ at $2.5 \mathrm{GHz}$.
After eight stress cycles, the gain of each prototype with the reflector was also measured to evaluate the effect of the repeated washing on the radiation properties. The values of 


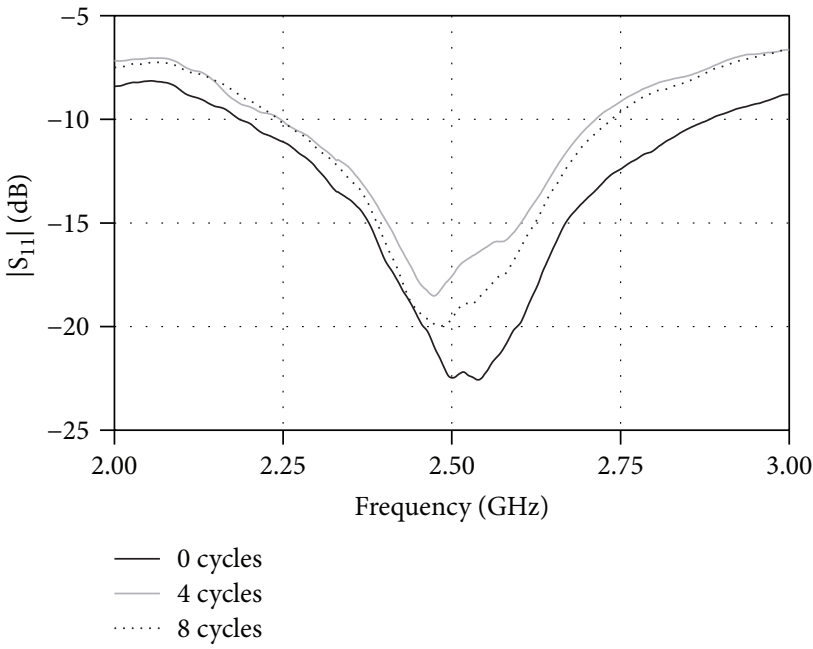

(a)

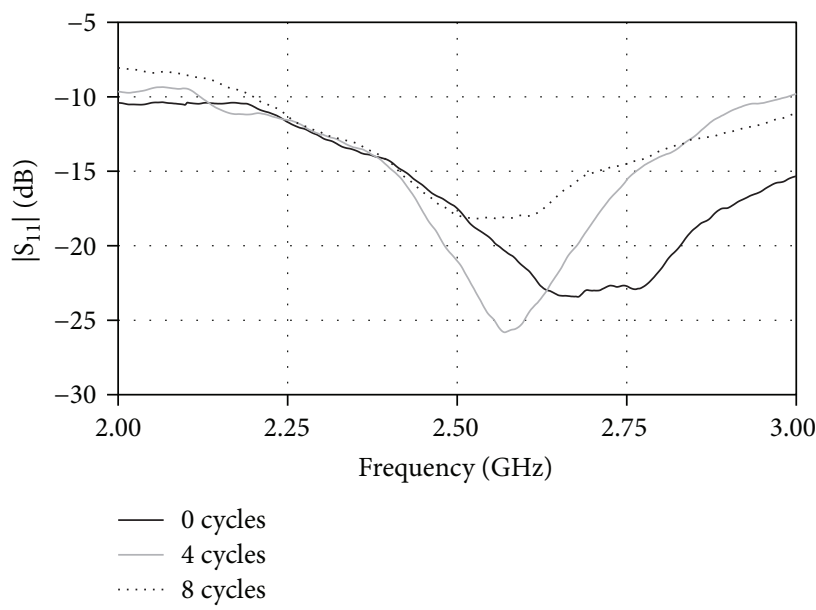

(c)

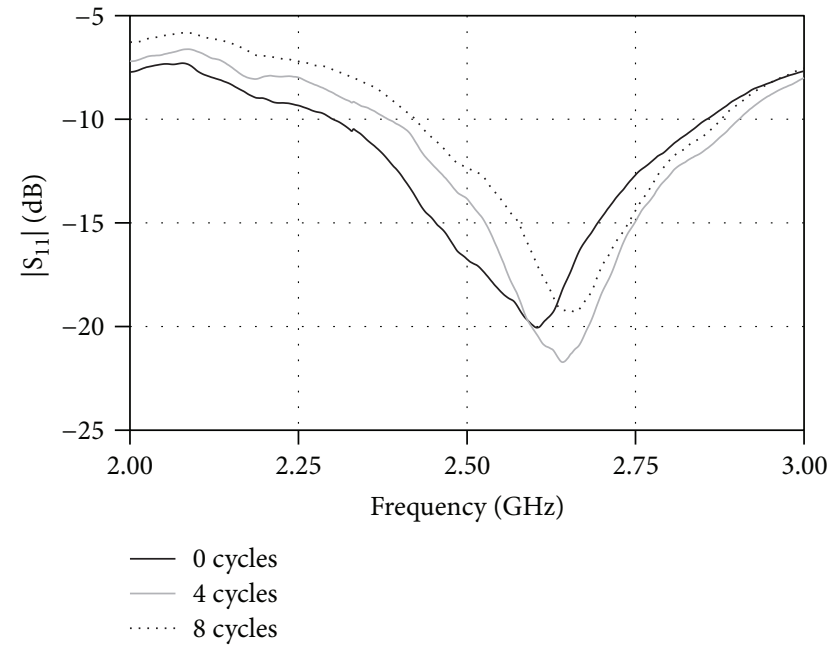

(b)

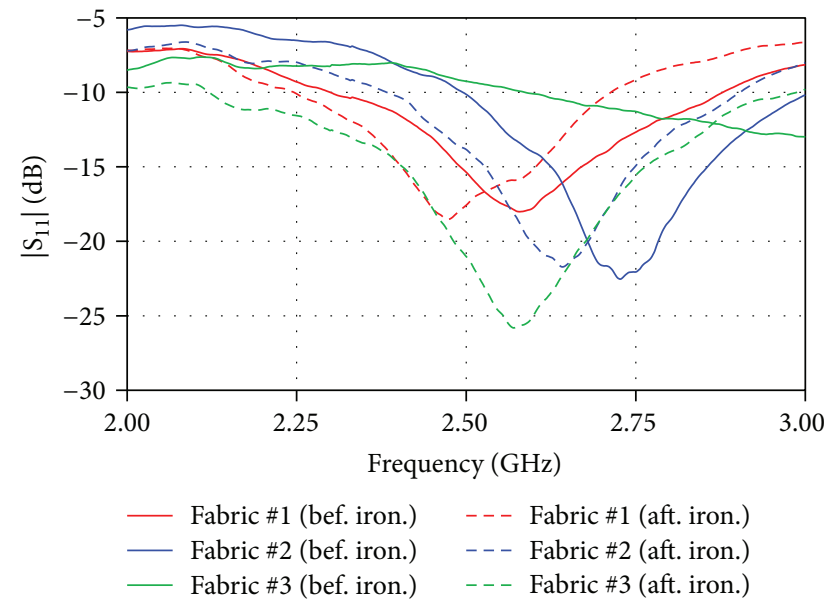

(d)

FIGURE 8: Results of the durability test performed on the prototypes shown in Figure 5: (a) prototype fabricated exploiting Fabric \#1; (b) Fabric \#2-based prototype; (c) prototype based on the use of the Fabric \#3; (d) effects of the feed-line unsticking on the antenna frequency behavior.

TABLE 2: Comparison between gain measured at $2.5 \mathrm{GHz}$ before and after the durability tests.

\begin{tabular}{lcc}
\hline \multirow{2}{*}{ Prototype (with the reflector) } & \multicolumn{2}{c}{ Max. gain $(\mathrm{dB})$} \\
& \multicolumn{2}{c}{ @ 2.5 GHz, $\varphi=90^{\circ}$} \\
& Before & After \\
\hline Fabric \#1 & 5.23 & 4.28 \\
Fabric \#2 & 5.54 & 4.40 \\
Fabric \#3 & 5.70 & 3.73 \\
\hline
\end{tabular}

gain measured at $2.5 \mathrm{GHz}$ before and after the durability test are compared in Table 2.

For all the three prototypes, it can be noticed that a reduction of the gain varies from about $0.9 \mathrm{~dB}$ (for the Fabric \#1) to about $2 \mathrm{~dB}$ (for the Fabric \#3).

Finally, from a merely aesthetic point of view, the best result was achieved for the Fabric \#3. In fact, also after repeated washing cycles, no oxidation stains are visible on the conductive parts.
The results reported in this paper demonstrate that the major durability issues of adhesive NWCFs are related to the quality of the adhesive and to its resistance to washing. In this regard, a possible strategy to further improve the durability of the adhesive NWCF-based antennas could be to use conformal protective coatings $[36,38]$ or to use nonconductive threads for stitching the conductive parts to the textile substrate [29].

\section{Conclusions}

In this paper, the effects of repeated stress cycles (cold water washing, outdoor drying, and ironing) on adhesive nonwoven conductive fabric-based antennas were investigated. Three antenna prototypes fabricated on a layer of denim cotton were exploited for the durability analysis. For the conductive parts, three different adhesive nonwoven conductive fabrics were used. The performance degradation was evaluated through $\left|S_{11}\right|$ measurements carried out through a VNA. 
This study demonstrates that the major durability issues of adhesive nonwoven conductive fabric-based antennas are related to washing resistance of the adhesive layer. In this regard, the best durability performance was observed for the material RS-CU-C4, whereas the fabric PBN II 1.3 exhibited the worst performance.

\section{Data Availability}

The data used to support the findings of this study are available from the corresponding author upon request.

\section{Conflicts of Interest}

The authors declare that there is no conflict of interests regarding the publication of this paper.

\section{Acknowledgments}

This work was supported by Fondo di Sviluppo e Coesione 2007-2013-APQ Ricerca Regione Puglia "Programma regionale a sostegno della specializzazione intelligente e della sostenibilità sociale ed ambientale-FutureInResearch.”

\section{References}

[1] N. Kumar, A. Aggrawal, and N. Gupta, "Wearable sensors for remote healthcare monitoring system," International Journal of Engineering Trends and Technology, vol. 3, no. 1, pp. 3742, 2012.

[2] S. Majumder, T. Mondal, and M. J. Deen, "Wearable sensors for remote health monitoring," Sensors, vol. 17, no. 12, p. 130, 2017.

[3] C. Garripoli, M. Mercuri, P. Karsmakers et al., "Embedded DSP-based telehealth radar system for remote in-door fall detection," IEEE Journal of Biomedical and Health Informatics, vol. 19, no. 1, pp. 92-101, 2015.

[4] L. Corchia, G. Monti, E. De Benedetto, and L. Tarricone, "Wearable antennas for remote health care monitoring systems," International Journal of Antennas and Propagation, vol. 2017, Article ID 3012341, 11 pages, 2017.

[5] M. Himashri and B. K. Jyotishi, "Efficient monitoring of elderly people by automatic activity recognition using wearable sensors," International Journal of Electrical, Electronics and Computer Systems, vol. 4, no. 7, pp. 2347-2820, 2016.

[6] L. Corchia, E. De Benedetto, G. Monti, A. Cataldo, and L. Tarricone, "Wearable antennas for applications in remote assistance to elderly people," in 2017 IEEE International Workshop on Measurement and Networking (M\&N), pp. 1-6, Naples, Italy, September 2017.

[7] C. Linti, H. Horter, P. Osterreicher, and H. Planck, "Sensory baby vest for the monitoring of infants," in International Workshop on Wearable and Implantable Body Sensor Networks (BSN'06), Cambridge, MA, USA, April 2006.

[8] P. Perego, G. Andreoni, R. Zanini, and R. Bellù, "Wearable biosignal monitoring system for newborns," in 2014 4th International Conference on Wireless Mobile Communication and Healthcare - Transforming Healthcare Through Innovations in Mobile and Wireless Technologies (MOBIHEALTH), pp. 271-274, Athens, Greece, November 2014.
[9] R. Nakamura and H. Hadama, "Target localization using multi-static UWB sensor for indoor monitoring system," in 2017 IEEE Topical Conference on Wireless Sensors and Sensor Networks (WiSNet), pp. 37-40, Phoenix, AZ, USA, January 2017.

[10] C. Glaros, D. I. Fotiadis, A. Likas, and A. Stafylopatis, “A wearable intelligent system for monitoring health condition and rehabilitation of running athletes," in 4th International IEEE EMBS Special Topic Conference on Information Technology Applications in Biomedicine, 2003, pp. 276-279, Birmingham, UK, April 2003.

[11] D. R. Seshadri, C. Drummond, J. Craker, J. R. Rowbottom, and J. E. Voos, "Wearable devices for sports: new integrated technologies allow coaches, physicians, and trainers to better understand the physical demands of athletes in real time," IEEE Pulse, vol. 8, no. 1, pp. 38-43, 2017.

[12] G. Monti, L. Tarricone, L. Corchia, and E. De Benedetto, "Wearable logo-antenna for GPS-GSM-based tracking systems," IET Microwaves, Antennas and Propagation, vol. 10, no. 12, pp. 1332-1338, 2016.

[13] J. Lilja and P. Salonen, "Textile material characterization for SoftWear antennas," in MILCOM 2009 - 2009 IEEE Military Communications Conference, pp. 1-7, Boston, MA, USA, October 2009.

[14] G. Monti, L. Corchia, and L. Tarricone, "UHF wearable rectenna on textile materials," IEEE Transactions on Antennas and Propagation, vol. 61, no. 7, pp. 3869-3873, 2013.

[15] G. Monti, L. Corchia, E. De Benedetto, and L. Tarricone, "A wearable wireless energy link for thin-film batteries charging," International Journal of Antennas and Propagation, vol. 2016, Article ID 9365756, 9 pages, 2016.

[16] G. Monti, L. Corchia, E. De Benedetto, and L. Tarricone, "Compact resonator on leather for nonradiative inductive power transfer and far-field data links," Radio Science, vol. 51, no. 6, pp. 629-637, 2016.

[17] G. Monti, L. Corchia, and L. Tarricone, "Logo antenna on textile materials," in 2014 44th European Microwave Conference, pp. 516-519, Rome, Italy, October 2014.

[18] G. Monti, L. Corchia, and L. Tarricone, "Textile logo antennas," in Proceedings of 2014 Mediterranean Microwave Symposium (MMS2014), pp. 1-5, Marrakech, Morocco, December 2014.

[19] M. A. R. Osman, M. K. Abd Rahim, N. A. Samsuri, H. A. M. Salim, and M. F. Ali, "Embroidered fully textile wearable antenna for medical monitoring applications," Progress In Electromagnetics Research, vol. 117, pp. 321-337, 2011.

[20] Y. Ouyang and W. J. Chappell, "High frequency properties of electro-textiles for wearable antenna applications," IEEE Transactions on Antennas and Propagation, vol. 56, no. 2, pp. 381-389, 2008.

[21] S. Zhang, A. Chauraya, W. Whittow et al., "Embroidered wearable antennas using conductive threads with different stitch spacings," in 2012 Loughborough Antennas \& Propagation Conference (LAPC), pp. 1-4, Loughborough, UK, November 2012.

[22] E. Moradi, T. Bjorninen, L. Ukkonen, and Y. Rahmat-Samii, "Effects of sewing pattern on the performance of embroidered dipole-type RFID tag antennas," IEEE Antennas and Wireless Propagation Letters, vol. 11, pp. 1482-1485, 2012.

[23] S. Ahmad, N. S. Saidin, and C. M. C. Isa, "Development of embroidered Sierpinski carpet antenna," in 2012 IEEE Asia- 
Pacific Conference on Applied Electromagnetics (APACE), pp. 123-127, Melaka, Malaysia, December 2012.

[24] A. Kiourti, C. Lee, and J. L. Volakis, "Fabrication of textile antennas and circuits with $0.1 \mathrm{~mm}$ precision," IEEE Antennas and Wireless Propagation Letters, vol. 15, pp. 151-153, 2016.

[25] A. Kiourti and J. L. Volakis, "Colorful textile antennas integrated into embroidered logos," Journal of Sensor and Actuator Networks, vol. 4, no. 4, pp. 371-377, 2015.

[26] T. Kaufmann, I. M. Fumeaux, and C. Fumeaux, "Comparison of fabric and embroidered dipole antennas," in 2013 7th European Conference on Antennas and Propagation (EuCAP), pp. 3252-3255, Gothenburg, Sweden, April 2013.

[27] B. Ivšić, D. Bonefačić, and J. Bartolić, "Performance of embroidered conductive yarn in textile antennas and microstrip lines," in 2015 9th European Conference on Antennas and Propagation (EuCAP), pp. 1-4, Lisbon, Portugal, April 2015.

[28] P. J. Soh, G. A. E. Vandenbosch, S. L. Ooi, and N. H. M. Rais, "Design of a broadband all-textile slotted PIFA," IEEE Transactions on Antennas and Propagation, vol. 60, no. 1, pp. 379384, 2012.

[29] I. Locher, M. Klemm, T. Kirstein, and G. Trster, "Design and characterization of purely textile patch antennas," IEEE Transactions on Advanced Packaging, vol. 29, no. 4, pp. 777-788, 2006.

[30] J. Trajkovikj, Robust wearable UHF antennas for security applications, Ph.D. Dissertation, Lab. Of Electrom. And Acoust., EPFL, Lausanne, CH, 2015.

[31] S. Yan, P. J. Soh, and G. A. E. Vandenbosch, "Wearable dualband magneto-electric dipole antenna for WBAN/WLAN applications," IEEE Transactions on Antennas and Propagation, vol. 63, no. 9, pp. 4165-4169, 2015.

[32] C. Loss, R. Gonçalves, C. Lopes, P. Pinho, and R. Salvado, "Smart coat with a fully-embedded textile antenna for IoT applications," Sensors, vol. 16, no. 6, p. 938, 2016.

[33] P. G. Elliot, E. N. Rosario, B. Rama Rao, R. J. Davis, and N. M. Marcus, "E-textile microstrip patch antennas for GPS," in Proceedings of the 2012 IEEE/ION Position, Location and Navigation Symposium, pp. 66-73, Myrtle Beach, SC, USA, April 2012.

[34] T. Acti, S. Zhang, A. Chauraya et al., "High performance flexible fabric electronics for megahertz frequency communications," in 2011 Loughborough Antennas \& Propagation Conference, pp. 1-4, Loughborough, UK, November 2011.

[35] R. Seager, S. Zhang, A. Chauraya et al., "Effect of the fabrication parameters on the performance of embroidered antennas," IET Microwaves, Antennas \& Propagation, vol. 7, no. 14, pp. 1174-1181, 2013.

[36] Y. Y. Fu, Y. L. Chan, M. H. Yang et al., "Experimental study on the washing durability of electro-textile UHF RFID tags," IEEE Antennas and Wireless Propagation Letters, vol. 14, pp. 466469, 2015.

[37] M. Toivonen, T. Björninen, L. Sydänheimo, L. Ukkonen, and Y. Rahmat-Samii, "Impact of moisture and washing on the performance of embroidered UHF RFID tags," IEEE Antennas and Wireless Propagation Letters, vol. 12, pp. 1590-1593, 2013.

[38] M. L. Scarpello, I. Kazani, C. Hertleer, H. Rogier, and D. Vande Ginste, "Stability and efficiency of screen-printed wearable and washable antennas," IEEE Antennas and Wireless Propagation Letters, vol. 11, pp. 838-841, 2012.

[39] http://www.sgadfors.com/Technologies/Fabrics/Glassmat.
[40] https://www.solianiemc.com/products/shielding-conductivetextile-fabrics.

[41] N. Chahat, M. Zhadobov, S. A. Muhammad, L. Le Coq, and R. Sauleau, " $60-\mathrm{GHz}$ textile antenna array for body-centric communications," IEEE Transactions on Antennas and Propagation, vol. 61, no. 4, pp. 1816-1824, 2013. 


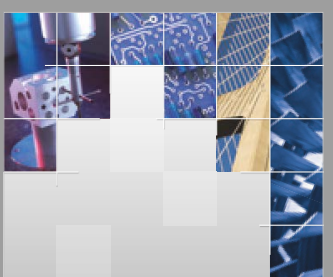

\section{Enfincering}
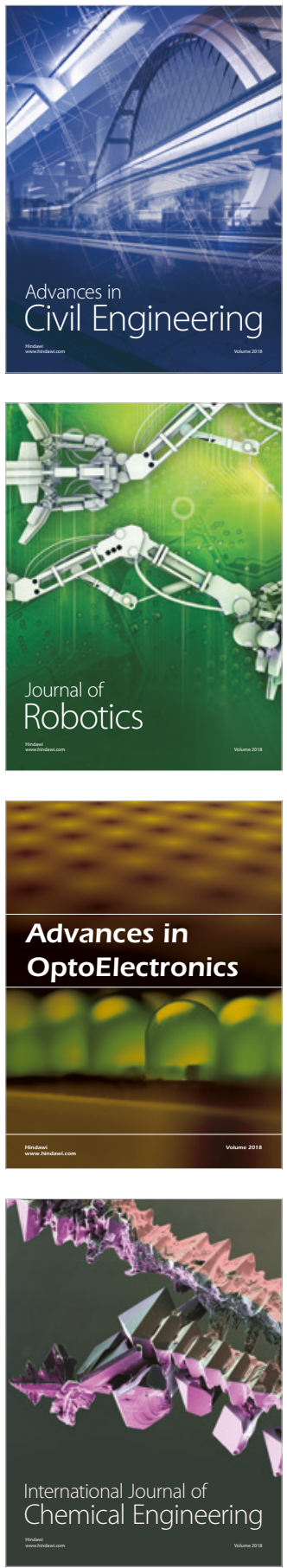

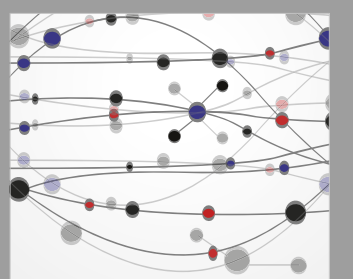

\section{Rotating \\ Machinery}

The Scientific World Journal

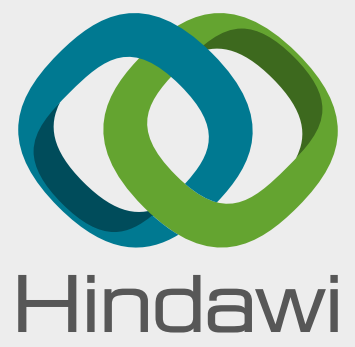

Submit your manuscripts at

www.hindawi.com
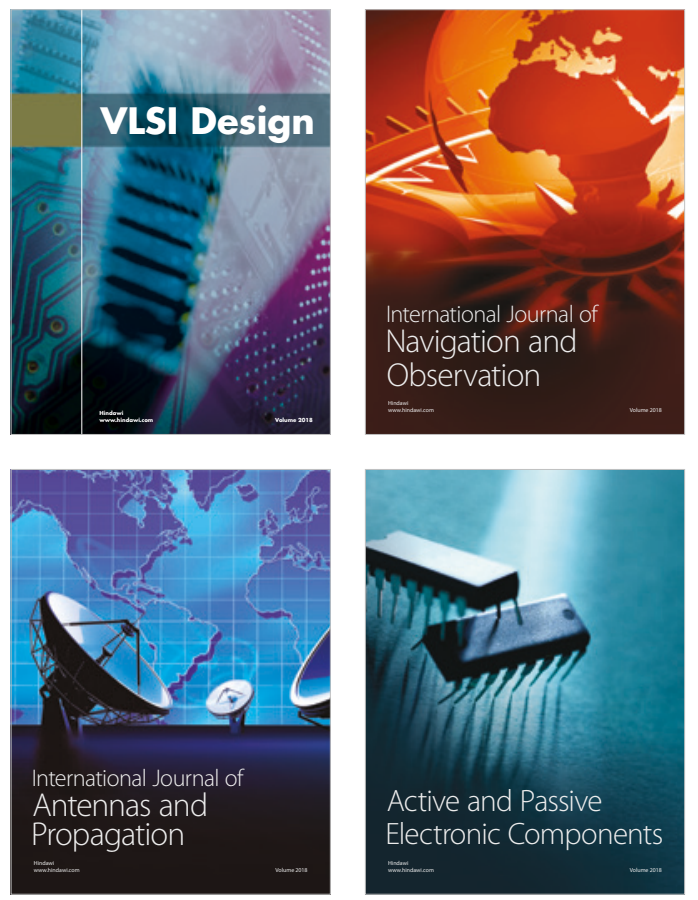
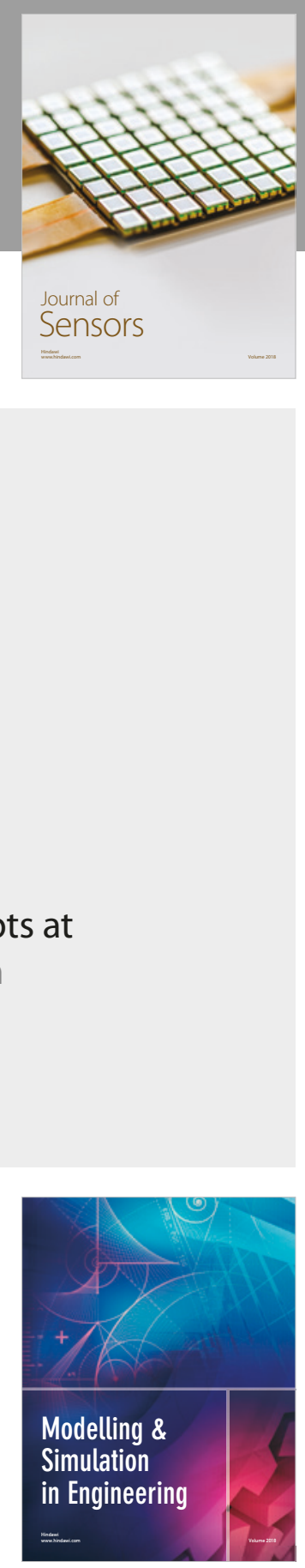

\section{Advances \\ Multimedia}
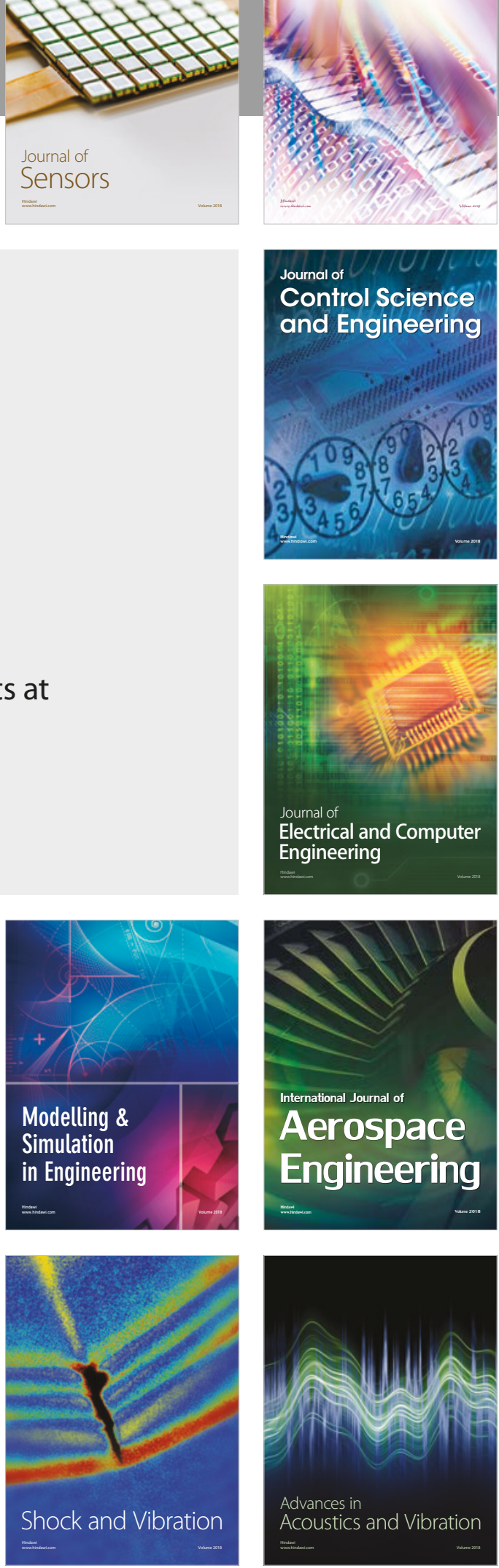